\title{
Modelling future changes in social vulnerability and bushfire risk
}

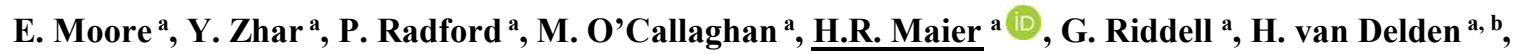 \\ M. Wouters ${ }^{\mathrm{c}}$ \\ ${ }^{a}$ School of Civil, Environmental \& Mining Engineering, University of Adelaide, Adelaide, South Australia, ${ }^{b}$ \\ Research Institute for Knowledge Systems, Maastricht, Netherlands, ${ }^{c}$ South Australian Department for \\ Environment and Water, Adelaide, South Australia \\ Email: holger.maier@adelaide.edu.au
}

\begin{abstract}
A natural hazard becomes a natural disaster when individuals, communities and infrastructure are impacted. The impact of a natural disaster is a function of the type and magnitude of the hazard, and the vulnerability of the people and assets exposed to the hazard. Consequently, bushfire risk is not only a function of bushfire likelihood and intensity, but also the social vulnerability of affected communities.

In this paper, a framework is presented that enables the spatial distribution of bushfire risk to be quantified by considering bushfire likelihood and social vulnerability. The framework also caters to the assessment of how this risk could change into the future in response to climate change and socio-economic development.

The framework is applied to the case study of Greater Adelaide, South Australia. The current distribution of social vulnerability is calculated based on a number of indicators and the current distribution of bushfire likelihood determined using the Unified Natural Hazard Risk Mitigation Exploratory Decision Support System (UNHaRMED), enabling the spatial distribution of current bushfire risk to be determined based on social vulnerability.

Plausible spatial distributions of future bushfire risk based on social vulnerability are obtained in response to a number of climate and socio-economic exploratory scenarios. The impact of climate change scenarios on bushfire likelihood is quantified with UNHaRMED. The impact of the socio-economic scenarios on social vulnerability is quantified using a combination of changes in the distribution of land use and population with the aid of UNHaRMED, as well as "clues" in the narrative scenario storylines about likely changes in factors affecting social vulnerability.

The results indicate that future changes in social vulnerability are likely to affect long-term bushfire risk in greater Adelaide, with spatial distributions of social vulnerability and bushfire risk changing in different ways under different plausible future scenarios. This enables areas of emerging risk to be identified, opening the door to long-term risk-reduction strategies to be targeted to these high-risk regions.
\end{abstract}

Keywords: Social vulnerability, bushfire risk, future risk, scenarios 


\section{INTRODUCTION}

A natural hazard becomes a natural disaster when individuals, communities and infrastructure are impacted (Smith, Martin \& Cockings 2016). The impact of a natural disaster is a function of the type and magnitude of the hazard, and the vulnerability of the people and assets exposed to the hazard (Dwyer et al. 2004; Frigerio \& De Amicis 2016). The hazard element includes the type of hazard, likelihood of its occurrence, severity, and the spatial distribution of the hazard (IPCC 2012). Vulnerability encompasses the vulnerability of the people and infrastructure exposed to the hazard, evaluating their ability to respond to and recover from a natural hazard (Cutter \& Finch 2008; Dwyer et al. 2004). The vulnerability element is usually referred to as social vulnerability and incorporates many diverse influencing factors (Cutter, Boruff \& Shirley 2003; Cutter \& Finch 2008; Dwyer et al. 2004; Frigerio \& De Amicis 2016). Chen et al. (2013) recognised that these influencing factors should consider the regional context, and others have considered vulnerability assessments tailored to the hazard under consideration (Chow, Chuang \& Gober 2012; Phung et al. 2016).

While there has been significant focus on modelling natural hazards in previous research (Dawson et al. 2011; Ghanbarpour, Saravi \& Salimi 2014; Hall, Sayers \& Dawson 2005; Wu, Yarnal \& Fisher 2002), relatively less attention has been paid to vulnerability. Of the research that has considered vulnerability, most has considered the spatial distribution of social vulnerability (Cutter, Boruff \& Shirley 2003; Cutter \& Finch 2008). However, little research has considered how social vulnerability and corresponding hazard risk evolve over time, which is an important consideration, as this has the potential to assist decision makers in the development of longterm planning approaches that better target areas with high social vulnerability (e.g. Newman et al. 2017).

Where temporal changes in social vulnerability have been considered, this has generally been based on extrapolation of past changes. For example, Cutter and Finch (2008) retrospectively investigated changing social vulnerability within the United States for discrete intervals of 10 years, dating back to 1960, and then used linear extrapolation of past trends to estimate vulnerability 2 years into the future. However, the merit of using exploratory scenarios for exploring future values of social vulnerability is well established in literature (Hall, Sayers \& Dawson 2005). Hall, Sayers and Dawson (2005) mentioned quantifying changes in social vulnerability by applying socio-economic scenarios to social flooding vulnerability indices, however, they did not present a methodology for achieving this. Furthermore, little consideration has been given to how changes in social vulnerability translate to changes in hazard risk. However, this is important, as focussing the spatial and temporal assessment of risk on social vulnerability allows risk reduction techniques to target the most vulnerable people exposed to the hazard.

In order to address the shortcomings in existing literature outlined above, the objectives of this paper are (i) to present a framework for calculating social vulnerability for a region of interest, incorporating how the spatial distribution of social vulnerability evolves over time under a range of different exploratory scenarios, and translating this into changes in risk due to different hazards; and (ii) to apply the framework to a case study of calculating the social vulnerability of greater Adelaide, the capital of South Australia. The Adelaide case study has been selected because Adelaide is experiencing an ageing population and instabilities in its local economy, making the projected trends of these demographics of interest to decision makers. The climate and location of Adelaide also causes the city to be at risk from a range of different natural hazards, including bushfire.

\section{METHODOLOGY}

\subsection{Case study}

Adelaide is the capital city of South Australia and has a population of approximately 1.3 million. It is situated between the Gulf St Vincent to its West, and the Mount Lofty Ranges to its East. Adelaide's climate is highly variable and Mediterranean. The combination of climate and location cause the city to be at risk from a range of different natural hazards, especially bushfire. In recent years, Adelaide has experienced an ageing population, as well as instabilities in its economy due to a shift from manufacturing to more service based industries. The projected trends in these demographics has led Adelaide's future social vulnerability, and the corresponding impact on hazard risk, to be of interest to decision makers.

\subsection{Social vulnerability}

The approach to determining the spatial distribution of social vulnerability for Greater Adelaide is shown in Panel (a) of Figure 1, which was done at a $100 \mathrm{~m} \times 100 \mathrm{~m}$ spatial resolution. The indicators used to assess social vulnerability in each $100 \mathrm{~m}$ by $100 \mathrm{~m}$ cell are shown in Table 1 , which cover a range of socio-economic characteristics that may affect someone's ability to respond to and recover from a hazard. For example, age may capture the possible difficulties young and elderly people may have evacuating by themselves in the event 
of a hazard. Education may capture the potential inability of people with lower levels of education to understand information related to risk, and their possible reluctance to evacuate as a result of misunderstanding the severity of the risk. The indicators used also consider socio-economic characteristics that affect the ability of someone to recover after a hazard event, including personal wealth, which captures how low-income communities may have low individual and community financial resources to recover, as well as how low-income households are also more likely to be un- or under-insured.

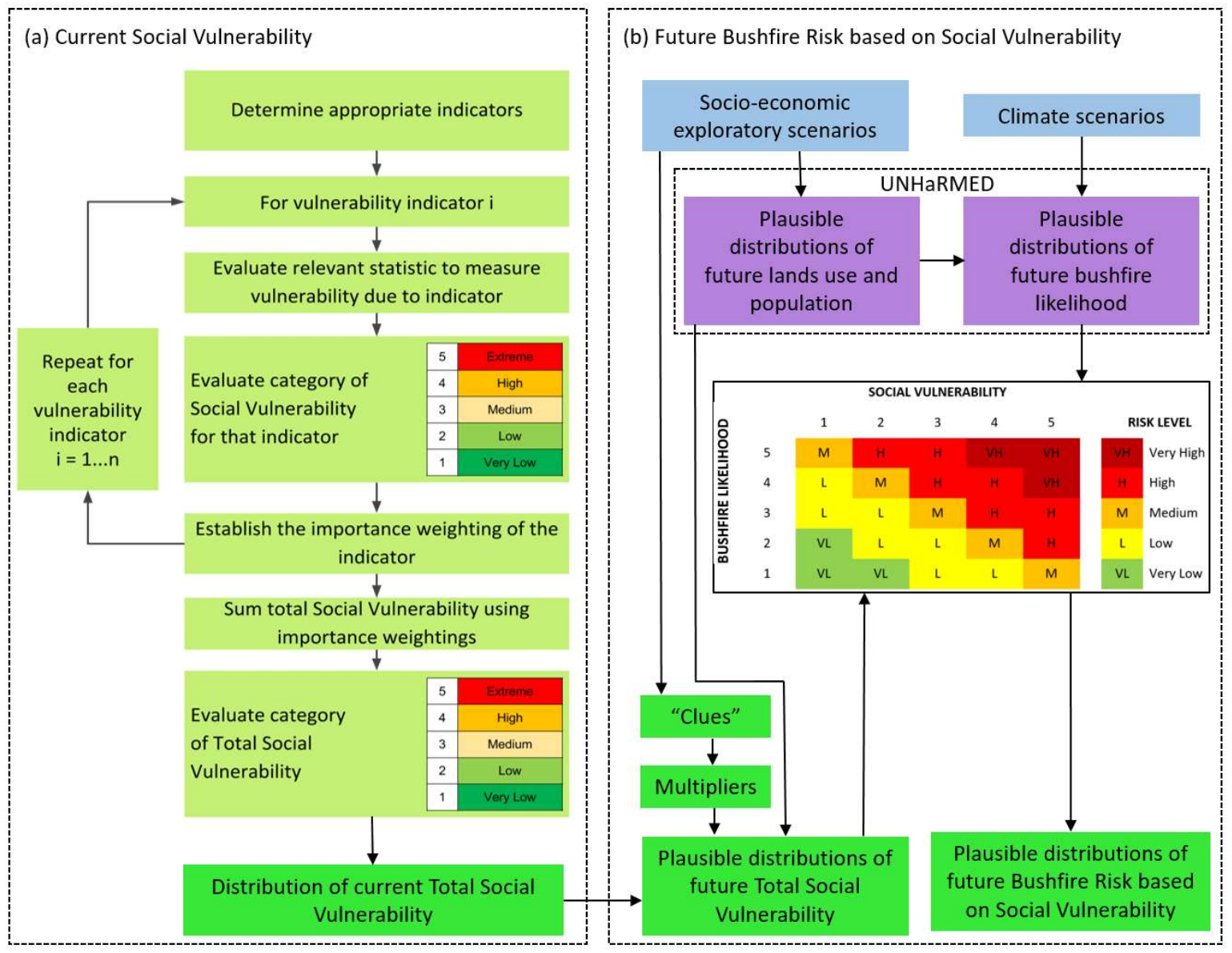

Figure 1. Proposed approach for calculating the current and plausible future distributions of social vulnerability and bushfire risk based on social vulnerability

Each indicator was quantified using a relevant statistic, values of which were obtained from the 2011 Census data for each State Suburb Code (SSC) (Australian Bureau of Statistics 2017). For example, social vulnerability due to age was assessed by evaluating the proportion of the population who are considered young (usually $<$ 14 years) or elderly (usually $>65$ years). These raw indicator statistics were then used to evaluate social vulnerability on a scale of 1 to 5 (Very Low to Very High). An advantage of using 5 categories to define Social Vulnerability is that the output maps can be easily applied to a risk assessment to produce hazard risk maps, as most risk assessments, such as Australian National Emergency Risk Assessment Guidelines (ANERAG) (Australian Government Attorney-General's Department 2015), use 5 categories of risk priority.

Ideally, quantified bounds for the social vulnerability categories are defined for each indicator variable with input from decision makers. However, in the absence of such input, the bounds were quantified from the percentile ranking of a cell's indicator value in relation to the other cells in the spatial domain. Specifically, very low social vulnerability values were allocated to the bottom $20^{\text {th }}$ percentile, low vulnerability values to between the $20^{\text {th }}$ and $40^{\text {th }}$ percentile, medium vulnerability values to between the $40^{\text {th }}$ and $60^{\text {th }}$ percentile, high vulnerability values to between the $60^{\text {th }}$ and $80^{\text {th }}$ percentile and very high vulnerability values to between the $80^{\text {th }}$ and $100^{\text {th }}$ percentile. For some indicators, a higher value corresponds to higher vulnerability (e.g. unemployment levels), whereas for others, a high value corresponds to low vulnerability (e.g. median income). 
As shown in Figure 1, total social vulnerability was calculated using a weighted sum of the social vulnerability values of individual indicators. The importance and relevance of different vulnerability indices depends on the differing objectives and goals of different stakeholder groups. Thus, the priorities of decision makers can be incorporated using importance weightings. In the absence of decision maker and expert input, equal weightings were applied to each of the vulnerability indices, to avoid assumptions of relative importance (Cutter, Boruff \& Shirley 2003). The total social vulnerability was then evaluated on a scale of 1 to 5, in the same manner as the individual indicators.

Table 1. Vulnerability indicators and their quantifiable metrics, sourced from the Australian Bureau of Statistics

\begin{tabular}{|l|l|l}
\hline Indicators & Variables & \\
\hline Personal wealth & Estimates of Personal Income (weekly) - Median total income & $\$$ \\
\hline Young people & Estimated Resident Population - Persons - 0-14 years & $\%$ \\
\hline Elderly people & Estimated Resident Population - Persons - 65 years and over & $\%$ \\
\hline Employment & Labour Force Statistics - Unemployment rate & $\%$ \\
\hline $\begin{array}{l}\text { English } \\
\text { Proficiency }\end{array}$ & Proficiency in Spoken English - Not proficient in spoken English & $\%$ \\
\hline Indigenous & Aboriginal and Torres Strait Islander - Proportion of population & $\%$ \\
\hline Family structure & Family Structure - Count of dependent children per parent & Dependents per parent \\
\hline Volunteering & Voluntary Work for an Organisation or Group & $\%$ \\
\hline New to region & Address One Year Ago - Elsewhere in Australia or Overseas & $\%$ \\
\hline Education & Highest Year of School Completed - Year 12 or equivalent & $\%$ \\
\hline Need assistance & Need for Assistance to undertake Core Activities & $\%$ \\
\hline
\end{tabular}

\subsection{Future bushfire risk based on social vulnerability}

Plausible distributions of future bushfire risk based on social vulnerability were obtained by combining plausible distributions of future bushfire likelihood and plausible distributions of future social vulnerability with the aid of a risk matrix (Figure 1, Panel (b)). This involves implementing a risk assessment process, which assesses social vulnerability against bushfire likelihood. As was the case for social vulnerability, bushfire likelihood was categorised in five discrete levels from very low to very high. A single value of bushfire risk, also divided into five categories (from very low to very high hazard risk), was then determined based on the combination of categorisation of both bushfire likelihood and social vulnerability, which has been adapted from the Australian National Emergency Risk Assessment Guidelines (ANERAG) (Australian Government Attorney-General's Department 2015). The risk assessment was repeated for each location to obtain spatial maps of bushfire risk.

Plausible distributions of future social vulnerability were obtained by modifying the distribution of social vulnerability obtained using the approach outlined in Section 2.2 (Figure 1, Panel (a)) based on different plausible socio-economic futures, as represented by various socio-economic exploratory narrative scenarios. This was achieved by considering changes in the distribution of land use and population, as well as changes in social vulnerability indicators (Figure 1). Changes in the former were obtained with the Unified Natural Hazards Risk Mitigation Exploratory Decision support system (UNHaRMED) (van Delden et al. 2019), whereas changes in the latter were obtained based on the approach suggested by van Delden (2005).

The first step in obtaining changes to the vulnerability of a particular indicator was to identify clues in the narratives about the vulnerability indicator under consideration. Clues are meaningful statements in the narrative that contain relevant information about a state, change in state, a quality, a trend, or an interaction relevant to the indicator (van Delden et al. 2005). For example, if the narrative for the scenario describes an "ageing population" for a certain region, this clue suggests an increase in the proportion of elderly people in the region, affecting the age indicator. From these clues, a multiplier was developed to represent the numerical change in the indicator, as described by the clue, using relevant quantitative information, such as regional strategic plans or projections from national bureaus of statistics. The projected social vulnerability values were then evaluated on a scale of 1 to 5 and projected values of different vulnerability indicators combined using the procedure outlined in Figure 1 and detailed above.

Three plausible future scenarios for Greater Adelaide were considered, as developed previously for this purpose by members of South Australia's State Mitigation Advisory Group (SMAG). These scenarios consider socioeconomic changes from 2013 to 2050, based on future challenges to mitigation and challenges to resilience. Silicon Hills represents the best-case scenario, where future challenges to mitigation and resilience are both low. In this scenario, Greater Adelaide moves into a well-balanced economy with highly skilled immigrants and engaged locals (Riddell et al. 2019). Cynical Villagers represents a future with low challenges to resilience 
and high challenges to mitigation, where there is low population growth, with an aging population and a less connected and more vulnerable community (Riddell et al. 2019). Ignorance of the Lambs represents the situation where there are low future challenges to mitigation but high future challenges to resilience, due to an increased commuter lifestyle and increased population growth (Riddell et al. 2019).

Plausible distributions of future bushfire likelihood were obtained using UNHaRMED (Figure 1). The bushfire likelihood model in UNHaRMED considers ignition potential, suppression capability and fire behaviour on a $100 \mathrm{~m} \times 100 \mathrm{~m}$ grid. The narrative scenarios result in changes in plausible changes in the distribution of land use and population, which affect ignition potential in the bushfire likelihood model. Future bushfire likelihood is also affected by climate change via the fire behaviour module. In this study, a relative concentration pathway of 8.5 (RCP 8.5) was used.

\section{RESULTS AND DISCUSSION}

\subsection{Social vulnerability}

As can be seen in Figure 2(a), the current social vulnerability in Greater Adelaide is highly spatially variable. The east and hills regions have the lowest overall social vulnerability, while the western regions have the greatest density of areas with high or very high social vulnerability. In the northern region, social vulnerability varies greatly, ranging from very low to very high. The areas of zero social vulnerability correspond to areas where there are no people.

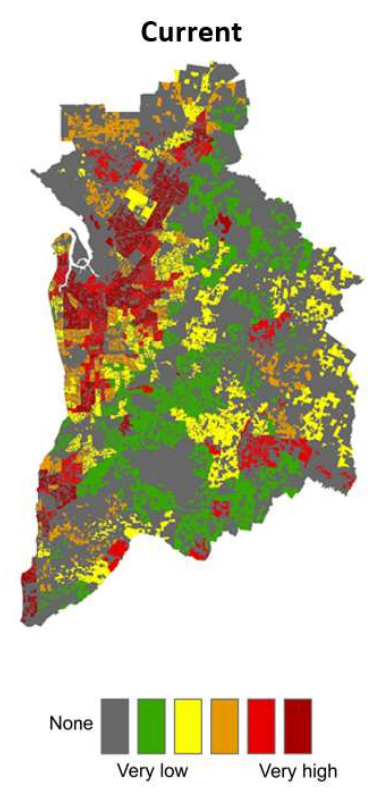

(a)

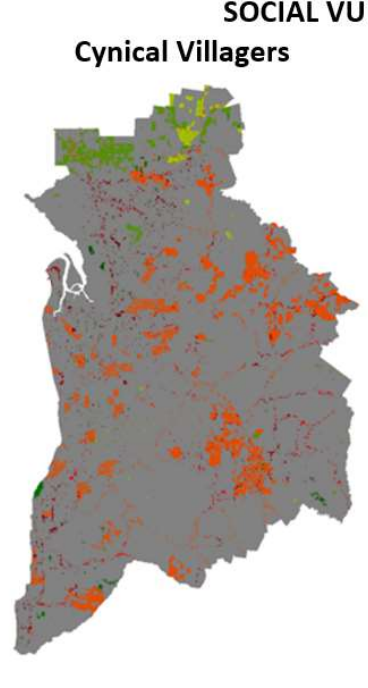

High increase

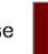

(b)
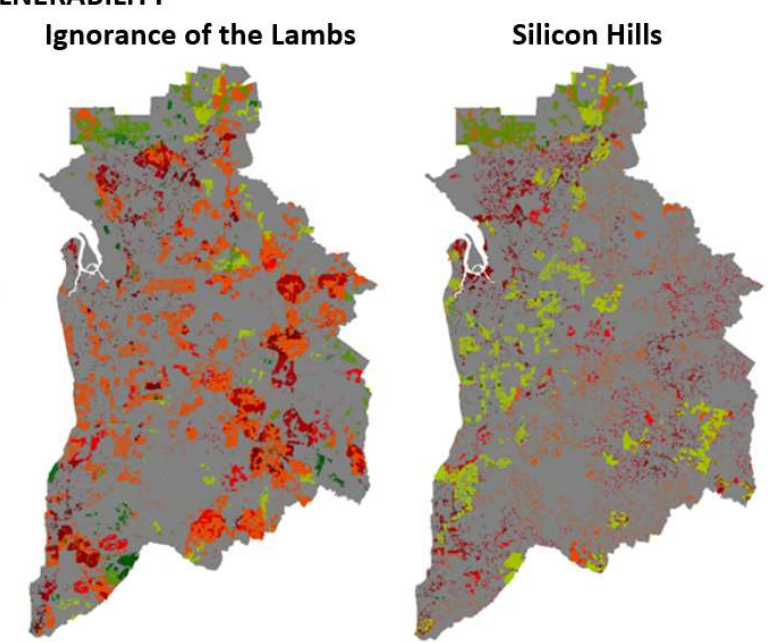

No change

(c)

(d)

Figure 2. Current (a) and projected social vulnerability in 2050 for greater Adelaide for Cynical Villagers (b), Ignorance of the Lambs (c), and Silicon Hills (d) scenarios

The changes in the total measure of social vulnerability between now and 2050 under the Ignorance of the Lambs, Silicon Hills and Cynical Villagers scenarios are also shown in Figure 2 ((b) to (d)). These changes are due to changes in the social vulnerability indicators projected in the scenario narratives. The Cynical Villagers and Ignorance of the Lambs scenarios predominantly show an increase in social vulnerability, while the Silicon Hills scenario shows a larger number of areas where social vulnerability decreases. This is to be expected for Silicon Hills, as it is the best-case scenario, and so a majority of the 14 social vulnerability indicators are projected to decrease in social vulnerability across all regions of Greater Adelaide by 2050. 


\subsection{Bushfire risk based on social vulnerability}

The current distribution of bushfire risk based on social vulnerability is shown in Figure 3(a). As can be seen, most of the Adelaide hills region experiences a very low to medium bushfire risk, however there are several spots with a high risk. In the north and south of greater Adelaide, the bushfire risk is mostly medium or high. This is due to medium to very high social vulnerability, paired with predominantly medium hazard in the north and south. The inner metropolitan region of greater Adelaide, however, mostly experiences zero bushfire risk due to negligible bushfire likelihood because of no vegetation in this area.

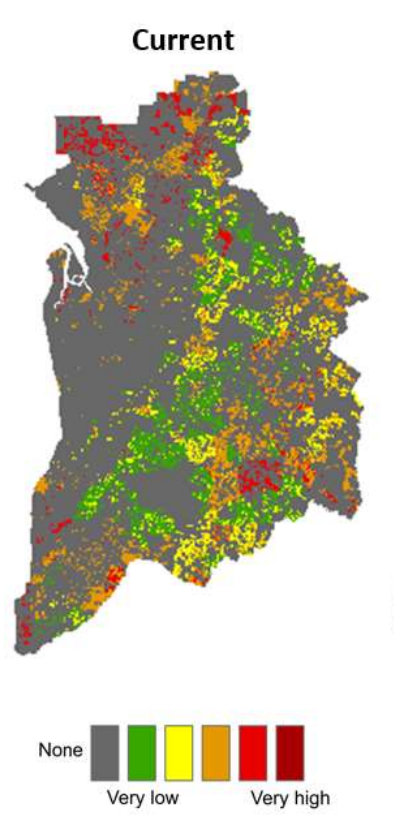

(a)

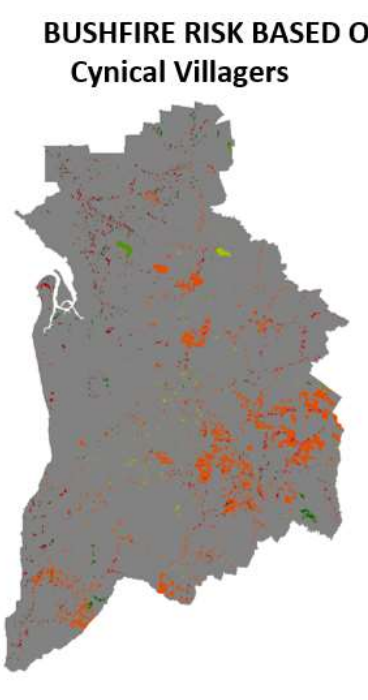

High increase III) II
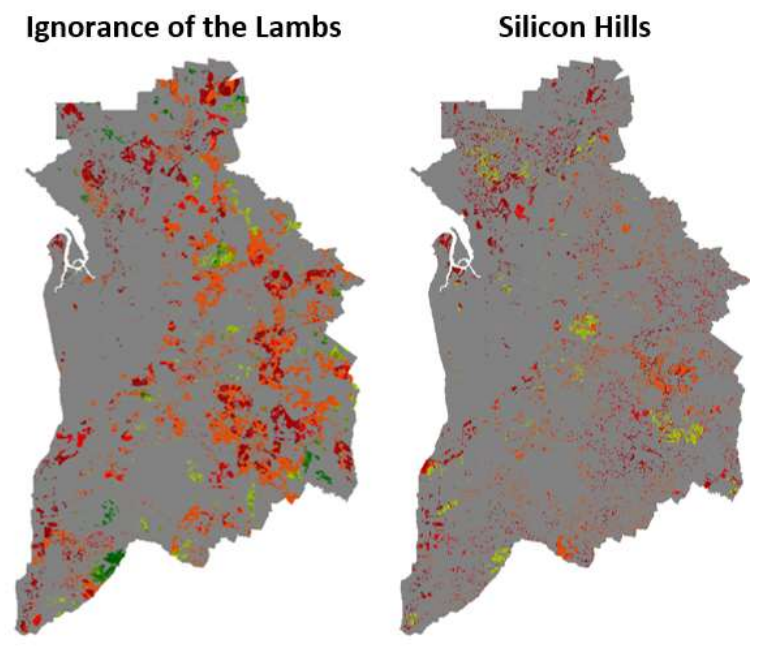

High decrease

(b)

(d)

Figure 3. Current (a) and projected bushfire risk based on social vulnerability in 2050 for greater Adelaide for Cynical Villagers (b), Ignorance of the Lambs (c), and Silicon Hills (d) scenarios

Projected changes in bushfire risk under the three exploratory scenarios are also shown in Figure 3 ((b) to (d)). The Silicon Hills scenario shows the highest decease in bushfire risk in 2050, particularly in the hills and north. This is due to a decrease in social vulnerability and negligible change in bushfire likelihood in these areas under this scenario. The scattering of areas with increased bushfire risk for this scenario may be attributed to changes in land use from a land use with no social vulnerability in 2015 to a community based land use in 2050. The Ignorance of the Lambs scenario shows the greatest change in bushfire risk. Most locations have a high increase in risk as a result of the large increases in social vulnerability projected by this low community resilience scenario. The large migration and development of urbanised centres in the hills and north also results in pockets of high increase in bushfire risk in the north, hills and south.

\section{SUMMARY AND CONCLUSIONS}

In previous studies, the primary focus of long-term natural hazard risk assessments has been on the magnitude of hazards and their economic impact, with little consideration given to the people impacted and their vulnerabilities. In particular, long-term changes in social vulnerability and the impact of these changes on natural hazard risk in the future has not been considered. The proposed approach presents a methodology for calculating spatially explicit social vulnerability maps based on a number of indicators, which have been identified in the literature as relevant factors contributing to social vulnerability. The proposed approach allows changes in long-term social vulnerability to be explored using scenarios, by presenting a methodology for quantifying projections of the social vulnerability indicators. The social vulnerability maps can be combined 
with bushfire likelihood maps to produce bushfire risk maps, enabling the impact of changes in social vulnerability on bushfire risk to be explored.

The approach was applied to a case study in greater Adelaide, South Australia. The results were used to develop an understanding of the influence of social vulnerability on long-term bushfire risk. The results demonstrated how changes in social vulnerability in the future are likely to affect long-term bushfire risk in greater Adelaide, with spatial distributions of social vulnerability and bushfire risk changing in the future under all three socioeconomic scenarios. From this study, areas that are likely to experience high social vulnerability and bushfire risk in the future across multiple scenarios were identified. By identifying these problem areas, long-term planning and risk reduction techniques can be targeted to these high risk regions.

\section{REFERENCES}

Australian Bureau of Statistics 2017, Australian Census Data by Region, Australian Bureau of Statistics, Australia, viewed April 2017, <http://stat.abs.gov.au/itt/r.jsp?databyregion>.

Australian Government Attorney-General's Department 2015, National Emergency Risk Assessment Guidelines, Second Edition, Australian Institute for Disaster Resilience.

Chen, W, Cutter, SL, Emrich, CT \& Shi, P 2013, 'Measuring social vulnerability to natural hazards in the Yangtze River Delta region, China', International Journal of Disaster Risk Science, 4(4), 169-181.

Chow, WTL, Chuang, W-C \& Gober, P 2012, 'Vulnerability to Extreme Heat in Metropolitan Phoenix: Spatial, Temporal, and Demographic Dimensions*', Professional Geographer, 64(2), 286-302.

Cutter, SL, Boruff, BJ \& Shirley, WL 2003, 'Social Vulnerability to Environmental Hazards', Social Science Quarterly, 84(2), 242-261.

Cutter, SL \& Finch, C 2008, 'Temporal and spatial changes in social vulnerability to natural hazards', Proceedings of the National Academy of Sciences of the United States of America, 105(7), 2301-2306.

Dawson, RJ, Ball, T, Werritty, J, Werritty, A, Hall, JW \& Roche, N 2011, 'Assessing the effectiveness of nonstructural flood management measures in the Thames Estuary under conditions of socio-economic and environmental change', Global Environmental Change, 21(2), 628-646.

Dwyer, A, Zoppou, C, Nielsen, O, Day, S \& Roberts, S 2004, Quantifying Social Vulnerability: A methodology for identifying those at risk to natural hazards, Geoscience Australia, Canberra, Australia.

Frigerio \& De Amicis 2016, 'Mapping social vulnerability to natural hazards in Italy: A suitable tool for risk mitigation strategies', Environmental Science \& Policy, 63, 187-196.

Ghanbarpour, MR, Saravi, MM \& Salimi, S 2014, 'Floodplain Inundation Analysis Combined with Contingent Valuation: Implications for Sustainable Flood Risk Management', Water Resources Management, 28(9), 2491-2505.

Hall, JW, Sayers, PB \& Dawson, RJ 2005, 'National-scale Assessment of Current and Future Flood Risk in England and Wales', Natural Hazards, 36(1), 147-164.

IPCC 2012, Managing the Risks of Extreme Events and Disasters to Advance Climate Change Adaptation: A Special Report of the Intergovernmental Panel on Climate Change, Cambridge University Press.

Newman J.P., Maier H.R., Riddell G.A., Zecchin A.C., Daniell J., Schaefer A., van Delden H., Khazai B., O'Flaherty M.J. and Newland C.P. 2017 Review of literature on decision support systems for natural hazard risk reduction: Current status and future research directions, Environmental Modelling \& Software, 96, 378409.

Phung, D, Rutherford, S, Dwirahmadi, F, Chu, C, Do, CM, Nguyen, T \& Duong, NC 2016, 'The spatial distribution of vulnerability to the health impacts of flooding in the Mekong Delta, Vietnam', International Journal of Biometeorology, 60(6), 857-865.

Riddell G.A., van Delden H., Maier H.R, Zecchin A.C. (2019) Exploratory scenario analysis for disaster risk reduction: Considering alternative pathways in disaster risk assessment, International Journal of Disaster Risk Reduction, 39, 101230.

Smith, A, Martin, D \& Cockings, S 2016, 'Spatio-Temporal Population Modelling for Enhanced Assessment of Urban Exposure to Flood Risk', Applied Spatial Analysis and Policy, 9(2), 145-163.

van Delden, H, Engelen, G, Inge, U, Hagen, A, van der Meulen, M, Vanhout, R \& BV., R 2005, Prelude: Quantification and Spatial Modelling of Land use/ Land cover Changes, Final Report of Study Contract No. 3476/B2004.EFA.51905 and the Amendment 1 to the latter, Research Institute for Knowledge Systems BV.

van Delden, H, Riddell, G, Vanhout, R, Maier, H, Newman, J, Zecchin, A, Dandy, G (2019) UNHaRMED framework report: a co-creation approach for the development and use of decision support systems for disaster risk reduction. BNHCRC Report 484 (https://www.bnhcrc.com.au/publications/biblio/bnh-5686).

Wu, S-Y, Yarnal, B \& Fisher, A 2002, 'Vulnerability of coastal communities to sea level rise: A case study of Cape May County, New Jersey, USA', Climate Research, 22, 250-270. 